\title{
Marcos conceptuales para un currículo crítico: una propuesta desde la pedagogía crítica brasileña, española y estadounidense
}

Conceptual frameworks for a critical curriculum: a proposal from

Brazilian, Spanish and American critical pedagogy

\author{
Volumen 20, Número 1 \\ Enero - Abril \\ pp. 1-27
}

\section{César Toruño Arguedas}

\section{Citar este documento según modelo APA}

Toruño Arguedas, César. (2020). Marcos conceptuales para un currículo crítico: una propuesta desde la pedagogía crítica brasileña, española y estadounidense. Revista Actualidades Investigativas en Educación, 20(1), 1-27. Doi. 10.15517/aie.v20i1.40124 


\section{Marcos conceptuales para un currículo crítico: una propuesta desde la pedagogía crítica brasileña, española y estadounidense} Conceptual frameworks for a critical curriculum: a proposal from Brazilian, Spanish and American critical pedagogy

Resumen: El presente ensayo se elabora a partir de la necesidad teórica de constituir marcos conceptuales y operacionales para la elaboración de propuestas curriculares desde un enfoque crítico. Esto se logra a partir de un análisis de los principales teóricos de la pedagogía crítica brasileña, española y estadounidense, entre los que destacan Henry Giroux, Michael Apple, Ernest House, Paulo Freire, José Gimeno, Ángel Pérez, Miguel Santos, Jurjo Torres y Lawrence Stenhouse. Las diversas producciones teóricas fueron sometidas a análisis de textos a partir de fichas que permitieron establecer las categorías de análisis y su respectivo procesamiento. El ensayo adquiere su justificación en el tanto, existen pocas propuestas de sistematización para la construcción de diseños curriculares desde una pedagogía crítica. Ante lo cual, resulta como aporte relevante para la discusión teórica, la construcción de los marcos conceptuales y operativos en las categorías de Educación-Centro Educativo, roles docente-estudiante, contextualización curricular (enseñanza, aprendizaje y evaluación) y conocimientos. Lo anterior permite concluir que la pedagogía crítica posee marcos conceptuales y operacionales delimitados que pueden favorecer el desarrollo de diseños curriculares críticos con énfasis en la contextualización curricular. Para lo cual, resulta necesario la incorporación de estas delimitantes dentro de la gestión e innovación curricular en las diferentes etapas del sistema educativo.

Palabras clave: Currículo, Currículo Crítico, Pedagogía Crítica, progresismo pedagógico.

Abstract: This essay is based on the theoretical need to establish conceptual and operational frameworks to elaborate curricular proposals from a critical approach. This is achieved through a analysis of the main theorists of Brazilian, Spanish and American critical pedagogy, among which are Henry Giroux, Michael Apple, Ernest House, Paulo Freire, José Gimeno, Ángel Pérez, Miguel Santos, Jurjo Torres and Lawrence Stenhouse. The various theoretical productions were determined from an analysis of texts from files that allowed establishing the categories of analysis and their respective processing. The essay acquires its justification in the meantime, there are few systematization proposals for the construction of curricular designs from a critical pedagogy. Therefore, as a relevant contribution to the theoretical discussion, the construction of the conceptual and operational frameworks in the Education-Educational Center categories, teacher-student roles, curricular contextualization (teaching, learning and evaluation) and knowledge. This allows us to conclude that critical pedagogy has defined conceptual and operational frameworks that can favor the development of critical curricular designs with an emphasis on curricular contextualization. For which, it is necessary to update these delimiters within the curriculum management and innovation in the different stages of the education system.

Key Words: Curriculum, Critic Curriculum, critical pedagogy, Pedagogic progressivism.

\begin{tabular}{l}
\hline Universidad Técnica Nacional, Costa Rica. Dirección electrónica: \\
ctoruno@utn.ac.cr ORCID: $\underline{\text { https://orcid.org/0000-0003-0476-7893 }}$
\end{tabular}

Ensayo recibido: 24 de junio, 2019

Enviado a corrección: 01 de octubre, 2019

Aprobado: 18 de noviembre, 2019 


\section{Introducción}

Los marcos conceptuales del sistema educativo (desde preescolar hasta la educación universitaria) son los ejes fundamentales de la conceptualización como institución cultural perteneciente a un proyecto político, económico y cultural delimitados son, por tanto, una clarificación de acción para guiar los procesos operativos del proyecto educativo propuesto por un sector educativo (dominante, progresista, alternativo u otro) y deben ser comprendidos dentro de una lógica dialéctica en donde el sistema educativo es el escenario de luchas entre el impulso de un proyecto hegemónico y las resistencias que ofrecen, sistematizadas o no, conscientes o no, sujetos y grupos de presión dentro del sistema. Bajo estas delimitaciones, resulta necesario establecer marcos conceptuales del sistema educativo desde la pedagogía crítica como insumo para la construcción de un currículo crítico como alternativa integral, pertinente y relevante frente a las limitaciones estructurales Enfoque Curricular Técnico imperante en las aulas y el Enfoque Curricular Práctico aspirado desde el currículo oficial.

A continuación, se expondrán principales aportes teóricos de referentes de las escuelas de pensamiento brasileña, española y estadounidense, estructurados a partir de las categorías de análisis: educación y centro educativo, roles docente-estudiante, mediación (enseñanza, aprendizaje y evaluación) y conocimiento; los cuales a su vez develan principios operacionales generales para las propuestas alternativas en educación. Para la elaboración de cada sub apartado se integraron los aportes en un diálogo inter autores mediados por un análisis crítico.

Las selecciones de estas escuelas de pensamiento se sustentan en la interacción dialéctica sostenida entre ellas, y sus principales teóricos, en las últimas décadas; la amplia y sistemática producción científica de los autores seleccionados (libros y artículos) y, finalmente, su influencia en la formación del currículo latinoamericano (con especial atención en la formación de la propuesta crítica desde Centroamérica). Se debe especificar que este ensayo realiza un proceso de construcción desde las supra citadas escuelas de pensamiento pero que, puede y deber complementado con los aportes teóricos y prácticos de diversos autores de la región latinoamericana, los cuales deberán ser integrados en futuros productos académicos vinculados a esta temática. 


\section{Educación y centro educativo: de la visión tradicional a la esperanza transformadora}

La concepción de la educación es una construcción cultural determinada por el contexto de la sociedad en la que se concibe por cuanto, al hacer "caso omiso de toda condición de tiempo y lugar, es que, implícitamente, se admite que un sistema educacional no tiene nada de real por sí mismo" (Durkheim, 1975, p. 46).

Cada concepción de educación es única, sin embargo, existen puentes comunes en las características asignadas a la educación ya sea en comparaciones temporales 0 espaciales. De este modo es posible considerar válidas y legítimas, para la actualidad, la crítica planteada por Rousseau cuando afirmaba que la educación "ni cumple el papel de formar ciudadanos ni el de formar personas" (Rousseau, 1985, p. 41) o la aspiración de que "Vivir es el oficio que yo quiero enseñarle, saliendo de mis manos él no será, convengo en ello, ni magistrado, ni soldado, ni sacerdote, será primeramente hombre" (Rousseau, 1985, p. 41), igualmente válida resulta la demanda de Rousseau de formar a las familias (padres y madres principalmente) por cuanto "¿Cómo es posible que se pueda lograr que un niño sea bien educado por quién no lo ha sido?" (Rousseau, 1985, p. 51) y su certera crítica a la "manía magistral y pedantesca es siempre la de enseñar a los niños cuanto ellos aprenderían mucho mejor por si mismos" (Rousseau, 1985, p. 82).

No obstante lo anterior, no puede obviarse la premisa de que "La educación se ha convertido en un conjunto clave de instituciones mediante las cuales el Estado intenta 'producir, reproducir, distribuir y cambiar' los recursos simbólicos, la conciencia misma de la sociedad" (Apple, 1996b, p. 86), proceso que se profundiza en los siglos XIX y primera mitad del siglo XX momentos en los cuales occidente vivió una revolución económica (Revolución Industrial y consolidación del capitalismo financiero) junto a las transformaciones políticasculturales (consolidación de Estados Nacionales, inserción laboral-social-política de la mujer, consolidación de movimientos populares ligados a alternativas políticas de izquierda, etc.) que desencadenaron en la estructuración de un sistema educativo acorde a esas nuevas circunstancias, por cuanto las escuelas son fundamentales para la "creación de condiciones para la acumulación de capital (escogiendo, seleccionando y certificando un grupo de estudiantes organizado jerárquicamente) y para la legitimación (manteniendo una ideología meritocrática falsa y además legitimando formas ideológicas para la recreación de la desigualdad)" (Apple, 1997a, p. 30) 
Esta relación (Estado-Sistema Productivo-Educación) encuentra su primer proyecto de sistematización en lo que Gimeno (1997) ha denominado como pedagogía por objetivos; proyecto pedagógico originado en Estados Unidos a inicios del siglo $X X$, que rápidamente consolida su influencia en occidente y que se sustenta en la extrapolación de principios de la producción industrial (conceptos, mecanismos de control, ordenamiento administrativo, estructura laboral y sistemas simbólicos) al sistema educativo, reduciendo la educación "a un mero entrenamiento en coherencia con la extrapolación del modelo industrial, donde formación es, ante todo, adquisición de destrezas concretas y útiles” (Gimeno, 1997, p. 22).

Así mismo, la relación Estado-Sistema Productivo-Educación debe ser comprendida en el marco de un proyecto hegemónico, que asume la hegemonía como "un proceso en el que los grupos dominantes en la sociedad se unen para formar un bloque y mantener el liderazgo sobre los grupos subordinados. Uno de los elementos más importantes que encierra esa idea es que un bloque de poder no tiene que utilizar la coerción" (Apple, 1996b, p. 39)

El proyecto hegemónico encuentra en la educación a una institución clave para su consolidación y expansión, en el tanto controla el "sistema cultural de una sociedad, del conocimiento que conservan y producen las instituciones, y de los actores que trabajan en ellas" (Apple, 1997a, p. 31), lo cual favorece la reproducción del sistema político-económico y cultural, así como el dominio de las posibles resistencias sin la coacción explícita.

La pedagogía por objetivos convivió, post Segunda Guerra Mundial y hasta la crisis de los energéticos en la década de 1970, con la consolidación de Estados de Bienestar o Estados Interventores en los cuales, además de una agenda de acceso (aumento de cobertura, infraestructura, contratación docente y ampliación de niveles y ofertas educativas) se reconstruye una agenda cultural de legitimidad al proyecto intervencionista.

Ante la crisis económica que experimenta occidente durante la década de los setenta y ochenta del siglo $\mathrm{XX}$, así como la expansión del paradigma económico de la Escuela de Chicago y el ascenso neo conservador, se da el ascenso de un nuevo proyecto hegemónico aperturista o neoliberal, en el cual la "concepción de la educación como un bien de consumo privado en vez de una inversión pública constituye un cambio significativo respecto de las políticas del período de expansión. Significa que la educación no es una responsabilidad pública" (House, 1999, p. 119).

La educación desde el modelo de la pedagogía por objetivos, establece un sistema autoritario donde "el educador es el que sabe y el que establece las normas, una vez que ha 
dilucidado con qué fines y con qué métodos ejerce su función. El educando queda reducido a receptor pasivo de la acción educativa" (Sotelo, 1999, p. 53), así mismo conceptualiza la educación como formadora de individuos en una sociedad de mercado, una misión que se consolida a partir de los "silencios, las filas, los exámenes, la compartimentación de los movimientos en el espacio y el tiempo, los premios y las penalizaciones, el trabajo y la obediencia" (Álvarez, 1999, p. 90). En síntesis, el sistema educativo; desarrolla "de forma explícita a veces y latente las más, una ideología cuyos valores son el individualismo, la competitividad y la insolidaridad, la igualdad formal de oportunidades y la desigualdad 'natural' de resultados en función de capacidades y esfuerzos individuales" (Pérez, 2000a, p. 20)

Frente a esta extrapolación industrial y re conceptualización del sistema educativo en el marco de las sociedades de mercado; diversos grupos sociales, políticos y educativos expresaron la necesidad de reconstruir el sistema vigente (ligados al reformismo político y social) o la urgencia para construir un nuevo sistema fundado en valores alternativos al capitalismo (vinculados al socialismo-comunismo), en esta última categoría surge la pedagogía crítica, también denominada pedagogía radical o pedagogía revolucionaria, la cual ofrece (en la década de 1950) una primera lectura marxista de la realidad educativa desde una posición de la reproducción (el sistema educativo establecía las condiciones de reproducción del sistema sin posibilidad de acción o transformación de sus agentes).

En la década de 1960, con el aporte de la escuela Neomarxista, Pierre Bourdieu (1997, 2001) revoluciona las lecturas del sistema educativo a partir de una posición de interacción dialéctica donde los sujetos podrían crear espacios de resistencia y transformación. Esta rama del pensamiento educativo encuentra su principal referente latinoamericano en Paulo Freire quien establece (Freire, 2005a) la correlación entre el pasado histórico (la poca experiencia democrática de Brasil por sus antecedentes de ser conquistado, colonia portuguesa y el uso de la fuerza militar) y las realidades educativas de Brasil, además de una denuncia a la educación tradicional o bancaria en la cual "la educación se transforma en un acto de depositar en el cual los educandos son los depositarios y el educador quien deposita" (Freire, 2005a, p. 78)

El análisis de Freire (2001) se sustenta en cinco premisas del sistema educativo alternativo, a saber: a) La lectura crítica del mundo, b) una utopía que guía la acción social, política y educativa, c) el reconocimiento de la utopía establece la obligación del sistema educativo de "promover la legitimidad del sueño ético-político de la superación de la realidad 
injusta" (Freire, 2001, p. 53), d) La pedagogía crítica se basa "en el amor, la humildad, la fe en los hombres, el diálogo se transforma en una relación horizontal en que la confianza de un polo en el otro es una consecuencia obvia" (Freire, 2015b, p. 74) y e) "la tarea progresista consiste en estimular y posibilitar, en las más diversas circunstancias, la capacidad de intervención en el mundo y nunca su contrario" (Freire, 2001, p. 70)

A partir de estas premisas, Freire desarrolla una amplia reflexión teórica sobre la construcción de una educación liberadora o problematizadora, en la cual se entiende la educación como "situación gnoseológica, en la cual el objeto cognoscible, en vez de ser el término del acto cognoscente de un sujeto, es el mediatizador de sujetos cognoscentes educador, por un lado; educandos, por otro" (Freire, 2015,b p. 61)

La propuesta de Freire transforma los pilares de la concepción de la educación, en primer lugar a replantear la epistemología clásica para establecer el conocimiento en un triángulo de interacción dialéctica con estudiante y docente; interacción en el marco de vínculos de construcción con y para el contexto (socio construccionismo o socio constructivismo), transforma los roles docente-estudiante, rompe el verticalismo educativo (docente-estudiante) y traslada el dominio del conocimiento del docente a la democratización de su construcción en todas las esferas educativas y del acto educativo.

Explícitamente, Freire (2008, p. 95) afirma que un sistema educativo progresista y democrático exige "una nueva manera de entender lo que es enseñar, lo que es aprender, lo que es conocer, de la que Vygotsky no puede estar ausente". Además de incorporar el socioconstructivismo (en la interacción del aula y del centro educativo con la sociedad), el amor y la utopía mencionados previamente, con la anterior definición Freire incorpora las aristas de democrática, alegre y capaz, junto a la caracterización de progresista, en el tanto define que "una educación progresista nunca puede, en la casa o en la escuela, en nombre del orden y de la disciplina, castrar la dignidad del educando, su capacidad de oponerse, e imponerle un quietismo negador de su ser" (Freire, 2012, p. 40)

Por tanto, al oponer a la educación bancaria (Freire, 2005) o tradicional, el autor construye un esquema de educación progresista diferenciadora no sólo en la construcción del conocimiento (dialógico) y la interacción con el contexto (función social de transformación), sino que además establece una educación en la que revolucionan las premisas de interacción, roles y posibilidades de docentes y estudiantes, con la advertencia de que ante este engaño “de la verticalidad de la programación, 'engaño’ de la concepción bancaria, caen muchas veces los revolucionarios, en su empeño por obtener la adhesión del 
pueblo hacia la acción revolucionaria" (Freire, 2005, p. 77), es decir, no puede denominarse como progresista, e incluso como alternativa, desde la pedagogía crítica a una propuesta pedagógica que mantenga los estatus quo de un sistema construido desde la extrapolación industrial, el conservadurismo y la hegemonía de un proyecto económico ante el cual sucumbe los idearios educativos.

El legado de Freire, y la escuela brasileña en general, constituyó el cimiento de conceptualización de la educación, desde la pedagogía crítica, que fue sintetizado en la definición de Giroux (2006, p. 61), el cual afirmó que "la educación se ocupa de deconstruir los conocimientos con el fin de que se entiendan más críticamente las experiencias y relaciones propias con la sociedad más amplia".

Desde la escuela de pensamiento norteamericana, la reivindicación de la educación como institución cultural en un entramado socio político se vincula a la denuncia, desde la pedagogía crítica, sobre el hecho de que los diferentes estudios pedagógicos no tienen "conciencia de los tipos de conflicto que se dan en las escuelas en relación a diferentes formas de conocimiento" (Giroux y McLaren, 1998, p. 80-81) y la demanda de que "podemos hacer lo pedagógico más político clarificando la manera en que la compleja dinámica de la ideología y el poder organiza las diversas experiencias y dimensiones de la vida escolar, a la vez que media en ellas" (Giroux, 2006, p. 60), en el tanto "las escuelas no son ideológicamente inocentes" (Giroux, 2006, p. 205), esta última afirmación es complementada por Giroux al indicar que como "personificación de un ideal, se refiere a las formas de aprendizaje y acción basadas en un compromiso para eliminar las formas de opresión de clase, raza y género" (Giroux, 2003, pp. 295-296).

En la anterior síntesis, Giroux establece una interacción elemental de la educación desde los estudios de la pedagogía crítica, es decir, una interacción dialéctica del sistema educativo con la esfera pública, un marco de aspiraciones, demandas de transformación, compromisos políticos y contextos, todo lo cual "se produce a partir de conflictos, tensiones y compromisos culturales, políticos y económicos que organizan y desorganizan un pueblo" (Apple, 1999, p. 153), con un claro horizonte: “la preparación de las personas más jóvenes para ser ciudadanas y ciudadanos activos, miembros solidarios y democráticos de y para una sociedad similar" (Torres, 1998, p. 14), así mismo, todo análisis del sistema educativo debe centrarse "en las cadenas nacional e internacional de formación de capitales, en las contradictorias necesidades del Estado, en las relaciones de clase y en las que existen entre el campo y la ciudad, que organizan y desorganizan ese país" (Apple, 1996b, p. 28) 
En esta postura, el centro educativo es más que un centro de reproducción académico o una extrapolación de fábrica social donde el producto (estudiante) es ensamblado en diferentes etapas de producción; por el contrario, es un espacio de construcción del conocimiento que exige rupturas en los procesos cotidianos y de mediación pedagógica. Sobre esta aspiración, Stenhouse (2003, p. 227) señala correctamente que la concepción tradicional de centro educativo centrado en el control, moralismo, rectitud y la tensión que una auténtica innovación "impone a la identidad y la competencia de los profesores, me parece que son importantes obstáculos con los que ha de enfrentarse toda escuela que pretenda realizar innovaciones"

El nuevo centro educativo se sustenta en la innovación entre los participantes, la cual se caracterizar por "dichas voces y negociar el derecho a experimentar" (Stenhouse, 2003, p. 228); esto implica comprender y asumir que junto a una propuesta progresista de educación y centro educativo, debe existir un margen de flexibilidad tal que permita a los sujetos reconstruir y transformar la propuesta.

Para elaborar un proyecto común de centro educativo, Santos (2003) sugiere los siguientes códigos: Código Semántico, Código Ideológico, Código Ético y Código de Grado, este último vinculado con los grados de exigencias, logros y otros. El código semántico implica la transformación del lenguaje para incluir desde la esperanza defendida por Freire (2005c) hasta aspectos de género y etnia (Giroux y McLaren, 1998), en tanto "Todas las tradiciones radicales, sean las centradas en las dinámicas de raza, clase o género, insisten en que se debe trabajar en colaboración para lograr un cambio" (Beyer y Liston, 2001, p. 233)

El código ideológico debe ser comprendido en el marco de la visibilización del proyecto hegemónico y su ideología así como la construcción de alternativas provenientes de distintas ideologías; bajo ningún supuesto el código ideológico debe asumirse con la promoción o imposición de un determinado precepto ideológico. Y, finalmente, el código ético exige el compromiso de los participantes con las nuevas formas de interacción y principios de transformación de las contradicciones de los centros educativos señalados por Santos (1999); a) es una institución de reclutamiento forzoso que pretende educar para la libertad, b) es una institución jerárquica que pretende educar en y para la democracia, c) es heterónoma que pretende desarrollar la autonomía, d) pretende educar para los valores y la vida, e) es epistemológicamente jerárquica que pretende educar la creatividad, el espíritu crítico y el pensamiento de la gente, f) es una institución sexista que pretende educar para la igualdad 
entre los sexos, g) es una institución pretendidamente igualadora que mantiene mecanismos que favorecen el elitismo, h) busca la diversidad pero que forma para competencias culturales comunes, i) está cargada de imposiciones pero pretende educar para la participación, j) la escuela es una institución aparentemente neutral que esconde una profunda disputa ideológica.

Desde esta concepción se denuncia que el sistema educativo y a los centros educativos "por sus contenidos, por sus formas y por sus sistemas de organización va induciendo paulatina pero progresivamente en las alumnas y alumnos las ideas, conocimientos, representaciones, disposiciones y modos de conducta que requiere la sociedad adulta" (Pérez, 2000a, p. 18), esta premisa no oculta el papel de la estructura tangible e intangible del sistema capitalista para la implementación de una estructura dominante y funcional a la estructura político-educativa.

Lo esbozado en este apartado permite establecer la educación como un sistema cultural construido en el marco de interacciones políticas, económicas, culturales y sociales de un proyecto hegemónico y las resistencias al mismo que alberga, en su seno, espacios de reproducción o resistencia, dominación y liberación y, ante todo, espacios para la reconstrucción cultural, siempre bajo la premisa de que los centros educativos "escuelas asignan personas y legitiman conocimientos, legitiman personas y asignan conocimientos" (Apple, 1997a, p. 57), motivo por el cual, desde la pedagogía crítica, se le reivindica como espacio de lucha para la liberación del individuo mediante una reformulación de las prácticas, conocimientos, actividades y sus agentes, esto último será analizado a continuación con la inclusión del elemento rol docente.

\section{Nuevas concepciones para nuevas interacciones: roles educador-educando}

La pedagogía crítica ha establecido, como una de sus prioridades de acción y reflexión, la transformación del roles docente-estudiante para superar la visión reproduccionista tradicional según la cual el "educador es el experto, mecánico que no filósofo, cuya función no consiste en pararse a pensar qué hay que hacer, sin en ofrecer una técnica eficiente para cumplir lo que se le dice que tiene que hacer" (Gimeno, 1997, p. 18).

Con respecto al estudiantado, la pedagogía crítica sostiene que "el análisis debe abarcar los factores que determinan el grado de participación y dominio de los propios alumnos/as sobre el proceso de trabajo y los modos de convivencia, de manera que pueda llegarse a comprender el grado de alienación o autonomía" (Pérez, 2000a, p. 23) 
Por tanto, la estructura conceptual de los roles docente-estudiante están, desde la pedagogía crítica, intrínsecamente vinculados; las demandas de ruptura con la visión tradicional del docente (verticalista, autoritario, dueño del monopolio de la verdad y el conocimiento, transmisor de conocimientos) exigen una contra acción de la transformación del papel del estudiante.

En el sistema educativo tradicional o Pedagogía por Objetivos, el docente cumplía un rol de técnico aplicador y los estudiantes de objetos vacíos que había de llenar del conocimiento universal y acoplar a los lineamientos morales de la sociedad, en este sentido, Freire (2015b, p. 83) sintetiza el rol del educador tradicional, funcionario de un sistema bancario o reproductivo, a partir de las siguientes premisas; a) el educador es siempre quien educa, el educando el que es educado, b) el educador es quien sabe; los educandos quienes no saben, c) el educador es quien piensa, el sujeto del proceso; los educandos son los objetos pensados, d) el educador es quien habla; los educandos quienes escuchan dócilmente, e) el educador es quien opta y prescribe su opción, los educandos quienes siguen la prescripción, f) el educador es quien actúa; los educandos son aquellos que tienen la ilusión de que actúan, en la actuación del educador, g) el educador es quien escoge el contenido programático; es educandos, a quienes jamás se escucha, se acomodan a él, h) el educador identifica la autoridad del saber con su autoridad funcional, la que se opone antagónicamente a la libertad de los educandos. Son éstos quienes deben adaptarse a las determinaciones de aquél $\mathrm{y}$, e) finalmente, el educador es el sujeto del proceso; los educandos meros objetos

La anterior síntesis devela premisas fundamentales de la lectura y comprensión de la pedagógica crítica sobre el rol docente en el sistema tradicional, en primer lugar la separación tácita entre educador y educando, el primero como sujeto conocedor y transmisor de conocimientos y el segundo como objeto que debe ser "llenado" de la cultura universal seleccionada por el proyecto hegemónico. Es un rol de poder autoritario en una estructura verticalista y opresora para el estudiante, el cual termina siendo delegado a objeto pasivo incluso en las estrategias de mediación.

La pedagogía crítica reitera la importancia estratégica del docente intelectual transformador (Giroux, 1990), es decir, el pedagogo que logra: a) asumir una tarea intelectual y asumirse como trabajador cultural, b) asumir y luchar contra las condiciones ideológicas y prácticas que le oprimen a él y al estudiantado, c) ejerce una crítica directa contra la visión tecnocrática de la educación, d) asume la escuela como un espacio de luchas de poder, 
control y proyectos hegemónicos, e) se compromete con un pensamiento y una acción crítica, f) convierte lo pedagógico en político y viceversa; además, según señala Flecha (1997), g) combina el lenguaje de la crítica con el lenguaje de la posibilidad, h) cruza los límites culturales, corporativos y disciplinares, i) vincula la pedagogía con los estudios culturales y j) basa la práctica educativa en la acción comunicativa, esto permite establecer una clara dicotomía entre el docente progresista y el tradicional o conservador,

el primero, con su sueño de transformación del mundo, el segundo, con su proyecto alienante de inmovilización de la historia; el progresista inmerso críticamente en formas de acción y en políticas pedagógicas coherentes con la comprensión de la historia como posibilidad; el conservador, autoritario, acrítico, de derecha o de izquierda, sin esperanza y carente de sueños, perdiéndose, sin muchas oportunidades de encontrarse, en una comprensión determinista de la historia (Freire, 2001, p. 127)

No obstante lo anterior, Freire establece dos características básicas que cualquier educador debe poseer para ejercer labores pedagógicas, en primer lugar el auto cuestionamiento sobre la concepción de hombre y mujer, por cuanto "Toda práctica educativa implica esta indagación: qué pienso de mí mismo y de los otros" (Freire, 2004a, p. 19); además, como segunda característica, establece que la labor docente exige "seriedad, preparación científica, preparación física, emocional, afectiva. Es una tarea que requiere de quien se compromete con ella, un gusto especial de querer bien, no sólo a los otros sino al propio proceso que ella implica" (Freire, 2005b, p. 8), en el tanto se "requiere competencia científica, claridad política e integridad ética" (Freire, 2008, p. 81).

Durante su amplio proceso reflexivo, desarrollado entre las décadas de 1950 y finales del siglo XX, Freire estableció, en diferentes escritos, un acercamiento a las características básicas que debe poseer el educador progresista, en primer lugar, debe predicar con el ejemplo "como padre, como profesor, como empresario, como empleado, como periodista, como soldado, científico, investigador o artista, como mujer, madre o hija" (Freire, 2001, p. 66)

Aunado a lo anterior, el o la educadora progresista tiene el deber de "colaborar en el proceso en el cual la debilidad de los oprimidos se va transformando en fuerza capaz de transformar la fuerza de los opresores en debilidad" (Freire, 2005a, p. 154), por cuanto el proceso y el acto educativo están intrínsecamente vinculados a la transformación de la 
mentalidad individual y colectiva, así como de las relaciones cotidianas y la estructura política-económica. Esto se une a la "profunda creencia en los hombres. Creencia en su poder creador" (Freire, 2005a, p. 83) no sólo como seres en el proceso aprendizaje sino, sobre todo, como actores revolucionarios del sistema mundo.

Coherente con la proyección de ideales producto de la izquierda del siglo XX, Freire establece que el educador progresista debe "descubrir las posibilidades -cualesquiera que sean los obstáculos- para la esperanza, sin la cual poco podemos hacer porque difícilmente luchamos, y cuando luchamos como desesperanzados o desesperados es la nuestra una lucha suicida, un cuerpo a cuerpo puramente vengativo" (Freire, 2005c, p. 25) y asumir como contenido prioritario aquel que es producto de "la devolución organizada, sistematizada y acrecentada al pueblo de aquellos elementos que éste le entregó en forma inestructurada" (Freire, 2015a, p. 76), esto permite que los estudiantes "en vez de ser dóciles receptores de los depósitos, se transforman ahora en investigadores críticos en diálogo con el educador, quien a su vez es también un investigador crítico. (Freire, 2015a, p. 83)

La pedagogía crítica exige romper con la pretendida neutralidad del sistema educativo, esto incluye que los(as) docentes asuman su lectura del mundo para poder "señalar que existen otras lecturas del mundo diferentes de la suya y hasta antagónicas en ciertas ocasiones" (Freire, 2005c, p. 139), permitiendo la diversidad en la construcción de pensamientos, identidades y acciones en el centro educativo y más allá de este. Además, exige "Criticar la arrogancia, el autoritarismo de intelectuales de izquierda o de derecha, en el fondo igualmente reaccionarios, que se consideran propietarios, los primeros del saber revolucionario, y los segundos del saber conservador" (Freire, 2005c, p. 103).

Coherente con lo anterior, Freire (2005c, p. 140) indica que se debe luchar en "favor de la democratización de la sociedad, que implica la democratización de la escuela como necesaria democratización, por un lado, de la programación de los contenidos y por el otro, de su enseñanza". Esto implica la ruptura de la estructura vertical de poder de la escuela tradicional, una ruptura epistemológica y psicológica del docente para dar paso a una nueva dinámica escolar donde los(as) estudiantes no sólo tendrán voz sino, más importante, tendrán incidencia directa en los contenidos a aprender, las mediaciones y evaluaciones, en la construcción de espacios de aprendizaje alternativo en el propio centro educativo y la reestructuración las narraciones educativas.

Lo anterior exige reconocer que "nadie lo sabe todo, nadie lo ignora todo" (Freire, 2008, p. 75) además del componente axiológico implica una reiteración del llamado a la 
transformación revolucionaria del paradigma docente, el compromiso vital de cada docente para realizar una ruptura con el verticalismo, academicismo, adulto centrismo y opresión que el sistema tradicional ha implantado en el rol docente. Además, señala que la humildad y la apertura permitirán que el educador "se encuentre permanentemente disponible para repensar lo pensado, para revisar sus posiciones; se percibe en cómo busca involucrarse con la curiosidad del alumno y los diferentes caminos y senderos que ésta lo hace recorrer" (Freire, 2008, p. 45).

Finalmente, Freire (2005c, p. 108) exige como objetivo "Desafiar a los educandos en relación con lo que les parece su acierto es un deber de la educadora o el educador progresista" y la necesaria comprensión del "derecho o en el deber de tener el derecho de luchar, de denunciar, de anunciar. Esta es la forma de amar indispensable para el educador progresista y que es preciso que todos nosotros aprendamos y vivamos" (Freire, 2008, p.77).

\section{La cosecha de las utopías pedagógicas: transformación de la contextualización curricular}

Según Freire (2001), la práctica educativa implica la presencia de sujetos (Educadoreducando), objetos de conocimiento, objetivos mediatos e inmediatos y, por último, métodos, procesos, técnicas de enseñanza y materiales didácticos, sin embargo, como ha sido explícito en apartados previos, la pedagogía crítica reivindica estos espacios como el resultado de "acuerdos y compromisos en los que los grupos dominantes, a fin de mantener su dominio, deben tener en cuenta los motivos de los menos poderosos" (Apple, 1996a, pp. 23-24), espacios de interacción dialéctica en un contexto determinado así como espacios de lucha entre un proyecto hegemónico y las posibilidades de resistencia. A continuación se analizará tres elementos sustantivos de la contextualización curricular: las concepciones de enseñanza y aprendizaje, mediación y evaluación.

\subsection{Enseñanza y aprendizaje: del verticalismo y fragmentación a la construcción dialéctica.}

Acertadamente, Gimeno (2000, p. 236) educación, enseñanza y currículum "son procesos de naturaleza social que permiten ser dirigidos por ideas e intenciones, pero que no se pueden prever del todo antes de ser realizados", por tanto, las premisas expuestas continuación se encuentran limitadas por el ejercicio real del acto educativo y, además, por el currículum oculto de cada docente, en el tanto este se planifica, se desarrolla y se evalúa "sin llegar a hacerse explícito en ningún momento en la mente e intenciones del profesorado ni, 
por supuesto, tener el asentimiento del alumno o de sus familias. Funciona de una manera implícita a través de los contenidos culturales, las rutinas, interacciones y tareas escolares" (Torres, 1998, p. 76)

A partir de lo anterior, es posible asociar la pedagogía crítica con tres premisas elementales para la práctica y la comprensión de la enseñanza, a saber: enseñar en un acto creador (Freire, 2005c, p. 105), "enseñar no es transferir conocimiento, sino crear las posibilidades de su producción o de su construcción" (Freire, 2006, p. 12) y "Quien enseña aprende al enseñar y quien aprende enseña al aprender" (Freire, 2006, p. 12)

Estas premisas, tanto epistemológicas como pragmáticas, establecen las características de la enseñanza integrando, implícitamente, los procesos de aprendizaje por cuanto desde esta postura pedagógica enseñanza y aprendizaje son un mismo componente del acto educativo en el cual docentes y estudiantes participan en igualdad para la construcción de aprendizajes para la liberación, por cuanto "se interesa por las estrategias de enseñanza y aprendizaje que facilitan este proceso de reflexión, de participación democrática y de ejercicio de la responsabilidad y solidaridad" (Torres, 1998, p. 200)

Sumado a lo anterior, Freire incorpora una desmitificación del proceso de enseñanzaaprendizaje, en el tanto se podría confundir la crítica de la pedagogía crítica (implicaciones) con la forma (técnica), ante lo cual aclara que el problema no radica en la clase magistral sino en "aquel tipo de relación educador-educando en que el educador se considera el único educador del educando, en que el educador rompe o no acepta la condición fundamental del acto de conocer que es la relación dialógica" (Freire, 2005c, p. 146)

Con respecto a la relación entre la enseñanza y la formación de pensamiento crítico (una de las grandes aspiraciones de la pedagogía crítica), establece que para lograr tal fin exige la creación y el ejercicio "de una seria disciplina intelectual que debe ir forjándose desde el nivel preescolar. Pretender la inserción crítica de los educandos en la situación educativa, en cuando situación de conocimientos, sin esa disciplina es una espera vana" (Freire, 2005c, p. 105), además, establece 27 principios que deben orientar la enseñanza (Freire, 2006), en el tanto esta exige: rigor metódico, investigación, respeto a los saberes de los educandos, crítica, estética y ética, la corporificación de las palabras en el ejemplo, riesgo, asunción de lo nuevo y rechazo de cualquier forma de discriminación, reflexión crítica sobre la práctica, reconocimiento y la asunción de la identidad cultural, conciencia del inacabamiento, reconocimiento de ser condicionado, respeto a la autonomía del ser del educando, buen juicio para evaluar cada instante de la práctica docente, humildad, tolerancia 
y lucha en defensa de los derechos de los educadores, la aprensión de la realidad, alegría y esperanza, convicción de que el cambio es posible, curiosidad, seguridad, competencia profesional y generosidad, compromiso, comprender que la educación es una forma de intervención en el mundo, libertad y autoridad, toma consciente de decisiones, saber escuchar, reconocer que la educación es ideológica, disponibilidad para el diálogo y querer bien a los educandos; esta última característica "significa la manera que tengo de sellar auténticamente mi compromiso con los educandos, en una práctica específica del ser humano" (Freire, 2006, p. 63), es decir, más allá de del vínculo formal (administrativo y de poder), el personal docente requiere formar vínculos afectivos en el tanto el o la estudiante es un sujeto activo de una humanidad compartida.

\subsection{Mediación: estrategias de transformación.}

La mediación se integra por las acciones y estrategias implementadas por enseñantes y aprendientes (bidireccional) para la construcción de los aprendizajes, estas son mediadas y son resultados de "el resultado de actividades, batallas, y compromisos de carácter político, económico y cultural” (Apple, 1996a, pp. 64). Esta temática ha tomado importancia durante las últimas décadas por cuanto, con "el uso creciente de sistemas de enseñanza preparados, según la forma de la enseñanza básica, no se necesita prácticamente interacción entre los profesores" (Apple, 1997a, p. 159)

Además, como señala Torres (1998, p. 99) los libros de texto "vienen a ser los encargados de tratar de conseguir la uniformidad en el interior del sistema educativo, a la vez que contribuye a definir la realidad desde una óptica acorde con los intereses de los grupos dominantes de cada sociedad", es decir, la pedagogía crítica no rivaliza con el objeto en sí (libro de texto) sino con la renuncia del docente como intelectual capaz de construir sus propios materiales para la contextualización curricular, por cuanto el libro de texto o cualquier otro insumo didáctico "importado" al aula, desconoce la premisa esencial de la pedagogía progresista: el reconocimiento de los conocimientos, sensibilidades, actitudes, destrezas y aspiraciones de los aprendientes-enseñantes como elemento vital del acto educativo.

Lo anterior devela el reto de la educación en la sociedad actual, es decir, la necesidad de consolidar procesos pedagógicos coherentes con postulados de una educación como institución cultural formadora para la liberación y un docente como intelectual que facilita procesos de enseñanza-aprendizaje desde posturas democráticas y rupturas epistemológicas, en palabras de Freire, implica consolidar una pedagogía del 
oprimido, es decir aquella que "ser elaborada con él y no para él, en tanto hombres o pueblos en la lucha permanente de recuperación de su humanidad" (Freire, 2005a, p. 42).

Ante esta aspiración, el propio Freire advierte que la "propaganda, el dirigismo, la manipulación, como armas de la dominación, no pueden ser instrumentos para esta reconstrucción" (Freire, 2005a, p. 72), un reiteración de los señalamientos del autor para que los y las docentes progresistas no caigan en la arena movediza de prácticas conservadoras con aspiraciones progresistas; motivo por el cual reitera que la mediación pedagógica progresista se sustenta en una metodología dialógica, es decir una "Práctica pedagógica en que el método deja de ser... instrumento del educador (en el caso, liderazgo revolucionario) con el cual manipula a los educandos (en el caso, los oprimidos) porque se transforman en la propia conciencia" (Freire, 2005a, p. 73).

La acción dialógica se sustenta en la premisa de que el "diálogo no impone, no manipula, no doméstica, no esloganiza" (Freire, 2015a, p. 153), además incorpora cuatro ejes de acción para su concreción: a) la colaboración, b) la unión, c) la organización y d) la síntesis cultural. La colaboración permite establecer puentes de acción entre enseñantesaprendientes, la unificación y organización permitirá a los(as) oprimidos(as) hacer de su "debilidad una fuerza transformadora, con la cual podrán recrear el mundo, haciéndolo más humano" (Freire, 2015a, p. 131) en el marco de la lucha por la transformación y liberación y la síntesis cultural permitirá la construcción de aprendizajes producto de la interacción entre el bagaje cultural propio de cada persona, el contexto, las realidades, lo académico y lo aspiracional. Con estos ejes, la propuesta de mediación dialógica busca eliminar la conquista que roba al oprimido(a) "su palabra, su expresividad, su cultura" (Freire, 2015a, p. 125), la división que aísla a los oprimidos, la manipulación de una burguesía que "presenta a las masas como su posibilidad de ascenso, instaurando la convicción de una supuesta movilidad social" (Freire, 2015a, p. 134) y la invasión cultural que "consiste en la penetración que hacen los invasores en el contexto cultural de los invadidos, imponiendo a éstos su visión del mundo, en la medida misma en que frenan su creatividad, inhibiendo su expansión" (Freire, 2015a, p. 137).

\subsection{Más allá de la medición: la evaluación para la consolidación del cambio educativo.}

La relación entre evaluación y la propuesta de una transformación educativa desde la pedagogía crítica es interdependiente, por lo cual se debe asumir la importancia de dicha 
relación ya que, en sus diferentes niveles (macro, meso y micro) se da una evaluación, desde el docente que evalúa (o mide) los conocimientos adquiridos por sus estudiantes (Gimeno, 2001) hasta el papel ideológico que cumple un determinado currículum (Kemmis, 1998).

El fondo de la reivindicación, "las escuelas no son ideológicamente inocentes, y tampoco son simplemente reproductoras de las relaciones e intereses sociales dominantes" (Giroux, 2006, p. 205), permite abordar el sistema educativo como un organismo complejo en sí, dinámico y en interacción dialéctica con la sociedad, generando un escenario donde se mezclan el discurso de la denuncia y la esperanza; en tanto permite establecer que, siguiendo a Juan Manuel Álvarez (1999, p. 174);

La evaluación educativa, y los conceptos que la van definiendo (rendimiento, calificación, acreditación...) es un constructo social y, por tanto, un invento, una convención susceptible de cambio, al que se le dan usos ideológicos y políticos confundidos con usos educativos. Se crea así la ilusión del consenso social respecto a los objetivos, los usos y las funciones hasta el punto que el mismo consenso nos hace pensar y ver que la evaluación no puede ser de otro modo...El lenguaje que se utiliza en la evaluación es esencialmente metafórico, cuando no técnico, y en muchos casos equívoco, cuando no tramposo, porque quiere ser neutral (cuando se utiliza para encubrir más que para comunicar, incluso cuando "dice"). Lo sustantivo pertenece a la esfera de lo oculto, de la suposición, se decide en otras instancias, adquiere el verdadero valor fuera del aula, por más que sea el aula el lugar visible donde podemos encontrar los primeros engarces que nos permitan el análisis crítico y constructivo de la situación

Así mismo, esta corriente de estudios no sólo se limitó a la reflexión crítica puesto que "ha aportado esquemas de análisis y nuevos conocimientos para reconstruir la idea de educación, como actividad permanente que se realiza en diferentes campos de acción práctica y de profesionalización" (Cabello, 2003, p. 43)

Dentro de estos nuevos esquemas de análisis, la pedagogía crítica devela el papel del Estado y la política, ya que ésta última "funciona para situar a la gente de forma diferente con respecto a la acometida de la riqueza y el poder, sino también provee las condiciones para la producción y adquisición del aprendizaje"(Giroux, 1997, p. 190), en tanto, se debe develar la influencia de las estructuras dominantes, y las posibilidades de resistencia, en el 
imaginario estudiante, es decir, su subjetividad así como las formas materiales y sociales de las relaciones sociales (Giroux y McLaren, 1998).

En este contexto, la evaluación se concibe como un proceso de diálogo, comprensión y mejora (Santos, 1995) que involucra intereses, en el proceso en sí, de sectores con desequilibrios de poder, valores y marcos ideológicos de los participantes por lo que él(la) evaluador(a), como participante del proceso con capacidad de organización estructural, debe asumir un compromiso ético con una evaluación que permita a todos(as) los(as) participantes interactuar en igualdad, expresar su voz (es decir, sus intereses, sus concepciones, visiones, otros) y ejercer un peso proporcional en la deliberación para la toma de decisiones.

La anterior definición se diferencia de la tradicional concepción de evaluación en tanto esta última se centra en la obtención de un resultado o producto como objetivo en sí, que es la finalización de la aplicación de una serie de instrumentos-técnicas objetivamente elaborados. Por el contrario, desde una visión crítica, la evaluación como proceso, es una serie de técnicas-instrumentos orientados por un fin de conocer y mejorar un determinado objeto-proceso, y que, por tanto, se debe desarrollar en todas las fases de la evaluación, siendo dialéctica la relación entre investigación, reflexión, resultados, acción. Desde esta posición, es más importante el ¿Cómo se obtuvo los resultados? A ¿Cuáles son los resultados?

En segundo lugar, en la visión tradicional se asume la evaluación como un proceso objetivo que no tenía un impacto más allá de lo evaluado es decir, era un proceso de implicaciones internas, no obstante con una visión crítica, es vital reconocer el impacto, directo e indirecto, de la evaluación, ya que detrás de una seudo objetividad y diseño estructurado neutralmente se puede esconder un interés por legitimar, mediante la evaluación, una serie de decisiones que afectarían la vida de los informantes e, incluso, sectores externo a la evaluación.

Así mismo, en la visión tradicional, el evaluador cumplía un rol médico que, mediante una serie de procedimientos estructurados, podía conocer los síntomas presentados y dar una serie de recomendaciones, como asesor externo, para que se tomaran las decisiones para suprimir los malestares. Sin embargo, en la visión crítica el evaluador no es un elemento externo que, descontextualizadamente, ofrecerá un proceso y conclusiones sino que, por el contrario, asumirá un rol de facilitador para que los grupos de interés puedan hacer escuchar sus voces y deliberar sobre su situación interna para que, ellos, puedan crear los mecanismos para mejorar las situaciones presentadas en el proceso. Esto está 
correlacionado con el principio de democratización de la evaluación, es decir, crear los mecanismos necesarios para evitar la concentración de poder en un grupo o sector integrante del proceso de evaluación, ya sea los patrocinadores u otro sector, ya que todos los sectores deben tener los espacios para hacer oír su voz en la deliberación para la toma de decisiones.

Todo lo anterior se enmarca dentro de la visión crítica de escuchar todas las voces de los sectores participantes en la evaluación, es decir, sus interés, expectativas, concepciones, ideologías, fórmulas para solucionar las situaciones, proyecciones, otros. Pero no sólo es escuchar sus voces ya que el evaluador debe tener la sensibilidad para transmitir, en su informe, la voz de cada sector, explicar su contexto pero no reinterpretando el mensaje y, además, escuchar los silencios de cada sector y tratar de descifrar porqué se producen (puede ser por temor a represalias, autocensura, otros) de tal forma, la evaluación podrá interpretar una realidad desde las subjetividades de sus integrantes y, por ende, ofrecer una colaboración más pertinente para el objeto en estudio. Claro está que, la visión crítica exige, también, escuchar y evidenciar las voces de participantes invisibles como lo son grupos de poder y resistencia.

Escuchar las voces de los participantes en una evaluación necesita que en el pre diseño de la evaluación se caractericen y operacionalicen los elementos básicos que guiarán dicha escucha, para lo cual es importante el aporte de Santos (1995) y House (1997) este último por la inclusión de un fundamento moral de la evaluación que puede ser ejercida por el docente, en su calidad de evaluador, y se encuentra integrada por: a) Igualdad Moral (todos tienen el mismo derecho de satisfacer sus necesidades), b) Autonomía Moral (a nadie se le puede imponer una voluntad y/o elección), c) Imparcialidad (ningún instrumento o metodología debe tener un sesgo para beneficiar a alguna de sus partes o sus intereses) y d) Reciprocidad (responsabilidad de los fuertes con los débiles en el proceso).

Acertadamente, Escudero et al (2001, p. 387) afirman que "llevar a cabo una evaluación es un proceso de toma de decisiones cuyo curso de acción requiere cierta planificación", es claro que una evaluación democrática deliberativa y crítica necesita una mayor planificación para asegurar los adecuados procedimientos de inclusión, diálogo y deliberación, para lo cual la persona docente puede tomar como referente las diez preguntas sugeridas por House y Howe (2001) para verificar que la evaluación responde a una concepción democrática deliberativa. 
Por último, Angulo (1999, pp. 215-216), propone que la evaluación en educación debe sustentarse en las siguientes premisas: 1) evaluar el sistema educativo debería significar evaluar todo el sistema educativo, 2) a información que genere la evaluación del sistema educativo debería ayudarnos a comprender con más profundidad los logros y dificultades, 3) se deben desarrollar, para la recolección de información, instrumentos y estrategias alternativas como estudios de casos y grupos de discusión, 4) los instrumentos y estrategias deben ser sensibles a las complejidades de los fenómenos sociales y educativos, 5) los instrumentos y estrategias deben promover la expresión libre de los participantes, 6) la validez de los instrumentos y las estrategias debe estar vinculada al uso, 7) la evaluación, los instrumentos y las estrategias deben estar sometidas a las complejidades del sistema educativo, 8) la evaluación educativa debe hacer explícito el concepto de escolaridad, educación y enseñanza que la sustentan, 9) la evaluación educativa no es un acto puntual, es dinámica, 10) la evaluación educativa debe responder al compromiso de todos los sectores y no ser responsabilidad de una sola entidad, 11) antes de iniciar un macro proceso de evaluación, se deben crear los consensos necesarios.

Por tanto, lo analizado en el presente sub apartado permite concluir que la evaluación cumple, en una propuesta progresista, el papel clave para democratizar el proceso educativo mediante la inclusión de voces, la construcción de nuevos mecanismos e instrumentos de evaluación y para cuestionar el papel mismo de la evaluación, además, y como afirma Freire (2001, p. 124) "en el campo de la decisión, la evaluación, la libertad, la apertura, la opción, se instaura la necesidad de la ética y se impone la responsabilidad. La ética se hace inevitable y su posible transgresión es un desvalor, nunca una virtud", por lo que resulta necesario la inclusión del apartado ético en la evaluación.

\section{Conocimiento: superando la especificidad académica.}

La conceptualización educación como institución cultural con procesos implicados en redes de poder, proyectos hegemónicos, currículum oculto y reproducción-resistencia en el contexto curricular, exige reconocer que responde a una selección de contenidos, es decir; "tomar decisiones sobre conceptos, habilidades, actitudes y valores que incluirán en el currículum, es un acto político y técnico-pedagógico" (Magendzo, 2008, p. 114)

La pedagogía crítica denuncia este andamiaje de poderes, muchas veces invisibles en la cotidianidad educativa, al tiempo que alerta que todo "aprendizaje relevante es en el fondo un proceso de diálogo con la realidad social y natural o con la realidad imaginada" 
(Pérez, 2000b, p. 113), esto decir, no existe conocimiento permanente, relevante, pertinente, significativo y transformador si no contiene interrelaciones con lo subjetivo y los contextos de las realidades en que se construye en el acto educativo.

En línea con lo anterior, Gimeno (2010a, p. 37), establece que;

La ideología progresista ha enfatizado, además, que es bueno, para progresar hacia una mayor equidad, el que toda esa amalgama social se mezcle en una escuela única con un tramo cada vez más prolongado de enseñanza común no diferenciada, lo que implica proporcionar una cultura común. ¿Qué contenidos son adecuados y aceptados en esa escolaridad común para una base social ten heterogénea? La respuesta vendrá de la mano de un proceso de diálogo político y cultural

Por tanto, el conocimiento conceptualizado desde una educación progresista implica una ruptura con el academicismo de la educación tradicional para dar forma a los principios de: a) el conocimiento es construido en un entorno social, b) el conocimiento como producto y herramienta de un determinado proyecto sociopolítico y pedagógico por lo que "seremos verdaderamente críticos si vivimos la plenitud de la praxis. Vale decir, si nuestra acción entraña una reflexión crítica que, organizando cada vez más el pensamiento nos lleve a superar un conocimiento estrictamente ingenuo de la realidad" (Freire, 2015a, p. 117) y c) el conocimiento como hecho cultural dinámico, variable y superable o transformable, por cuanto "la cultura es un sistema vivo en permanente proceso de cambio como consecuencia de la reinterpretación constante que hacen los individuos y grupos que viven en ella" (Pérez, 2000b, p. 71).

El proceso por el cual es construido dicho conocimiento ha sido señalado por Gimeno (2010b) como un proceso de selección cultural caracterizado por: decodificación cultural (del saber sabio a las políticas curriculares), cultura académica, transposición didáctica (científico y editores de textos), currículum enseñado, intercambio y comunicación significativa con el alumno y, por último, síntesis individual y colectiva. Estos conocimientos se transforman mediante los contenidos curriculares, es decir, "las distintas asignaturas y materias que se incluyen en el currículum" (Magendzo, 2008, p. 146)

Por tanto, desde una pedagogía crítica se puede establecer que no existe "el conocimiento" como defendió el sistema tradicional; por el contrario, existen los conocimientos que podemos categorizar como: 
a) Académicos. Conocimientos construidos en los niveles disciplinares, científicos, filosóficos y otros; estos conocimientos se construyen-transmiten en la formación docente. (Gimeno, 2010b)

b) Culturales, es decir, aquellos construidos dinámicamente en el centro educativo y en el contexto social de una región, un país, zonas de influencia inter regional y mundial (Gimeno, 2001).

c) Formales, es decir, aquellos "que las autoridades reconocidas como legítimas determinan que debe ser presentado a los alumnos" (Gvirtz y Plamidessi, 1998. p. 32), los cuales se establecen en los programas de estudio.

d) Explícitos. Vinculado con "lo que efectivamente los docentes transmiten a sus estudiantes" (Gvirtz y Plamidessi, 1998. p. 32)

e) Ocultos, aquellos contenidos productos del currículum oculto (Torres, 1998).

La reconstrucción de la concepción del conocimiento como producto cultural en un determinado contexto exige advertir que así "como es un error permanecer adherido a lo local, perdiendo la visión del todo, también es un error flotar sobre el todo sin referencia a lo local de origen" (Freire, 2005c, p. 112).

\section{Conclusiones.}

A partir de lo expuesto en el presente ensayo, se concluye que para la pedagogía crítica la educación y centro educativo son instituciones culturales que responden a los elementos contextuales de la sociedad en que se construyen así como en el proyecto hegemónico que enmarca las redes de poder, de esta forma se estructuró, al menos en occidente, un proyecto educativo ligado al desarrollo-consolidación del capitalismo ante el cual se estructura una alternativa pedagógica ligada, en sus orígenes, al marxismosocialismo y que puede ser denominada bajo el concepto de pedagogía crítica.

En la pedagogía crítica se denuncia la pedagogía por objetivos (Gimeno, 1997) del sistema tradicional y se plantea la educación como un espacio cultural que expresa, en forma implícita o explícita, los valores y conceptos del sistema capitalista (Pérez, 2000). Bajo esta premisa es posible encontrar espacios de resistencia y transformación (Bourdieu, 1997; 2001) donde destaca los aportes de Freire (2001; 2005) para establecer la necesidad de deconstruir el sistema dominante desde una educación con lectura crítica del mundo, contextualización del aprendizaje, utopías como referentes cotidianas, acción transformadora y la intervención en el mundo; así como las premisas de Giroux (2006) para establecer la 
educación como la deconstrucción de conocimientos para comprenderlos en el contexto y las posibilidades de transformación y bajo el reconocimiento de ser parte de un proyecto ideológico y las redes de poder. La educación es, ante todo, la institución cultural donde se visibilizan los conflictos, las tensiones y compromisos culturales y sociopolíticos (Apple, 1999).

Comprender la educación en relación al contexto y como espacio para la transformación de la sociedad es una necesidad e implica conceptualizar los centros educativos a partir de "escuelas progresistas" (Freire, 2008) en donde existe una reinvención de su papel para establecerlas como espacios de formación académica y democrática, de alegría y encuentro, con una apertura a diversos pensamientos y participación real de todos(as) (Pérez, 2000b), donde los participantes tienen el derecho a experimentar (Stenhouse, 2003), con nuevos códigos (Santos, 2003) que favorezcan el cambio estructural del sistema educativo.

En el marco de estas premisas, se estructura, un cambio del rol docente-estudiante para superar la división vertical, el tecnicismo y autoritarismo del sistema tradicional, para reconstruir un docente capaz de comprender que no existen consensos neutros (Torres, 1998) y un estudiante que debe ampliar sus márgenes de participación, convivencia y conciencia (Pérez, 2000a). Así mismo, se reivindica un docente como intelectual transformador (1990) que se asume como trabajador cultural, con pensamiento y acción crítica y, siguiendo a Flecha (1997) que usa el lenguaje de la esperanza, cruza los límites culturales, corporativos y disciplinares y basa su práctica en la acción comunicativa.

En relación con la contextualización curricular, se establece que la enseñanza es un acto creador (Freire, 2005) que supera la transmisión de conocimientos y que en esta hay aprendientes-enseñantes, es decir, ambos actores (educador-estudiante) aportan y aprenden. Este proceso, es la prioridad de la pedagogía crítica en el tanto, las estrategias de enseñanza-aprendizaje determinan las posibilidades de transformación (Torres, 1998).

La medicación es reivindicado como producto cultural y resultado de las batallas de redes de poder, tácito o no, en el sistema educativo y la sociedad (Apple, 1996a), y adquiere relevancia en el contexto de implantación de sistemas de enseñanza preparados (Apple, 1997a) como libros o materiales. Especial atención brinda contra materiales de textos si estos implican la renuncia de la acción docente $y$, sobre todo, por ser un intento de homogenización cultural (Torres, 1998) y un sistema de control cultural (Apple, 1996; 1997). 
El pilar de la mediación es la acción dialógica propuesta por Freire (2005; 2015b), la cual conlleva a una nueva evaluación diseñada desde el principio de un proceso de diálogo, comprensión y mejora (Santos, 1995), sustentada en una concepción democrática deliberativa (House, Howe; 2001) y una posición integraldesde una ética de planificación y acción (Freire, 2001).

Por último, se debe concluir que las categorías de análisis indicadas en este ensayo son un aporte inicial que puede ser nutrido, en futuras producciones científicas, con los aportes teóricos de diversos autores de la región latinoamericana para la consolidación de una lectura más pertinente y significativa en nuestro contexto.

\section{Referencias}

Álvarez, Fernando. (1999). La escuela y el espíritu del capitalismo. En Manzano, Pablo. (coord.), Volver a pensar la educación (pp. 87-95). Madrid, España: Morata.

Álvarez, Juan Manuel. (1999). Valor social y académico de la evaluación. En Manzano, Pablo. (coord.), Volver a pensar la educación (pp. 173-193). Madrid, España: Morata.

Apple, Michael. (1999). La política del saber oficial: ¿tiene sentido un currículum nacional? En Pablo Manzano (coord.), Volver a pensar la educación (pp. 153-171). Madrid, España: Morata.

Apple, Michael. (1996a). El conocimiento oficial. Barcelona, España: Paidós.

Apple, Michael. (1996b). Política Cultural y Educación. Barcelona, España: Paidós.

Apple, Michael. (1997a). Educación y poder. Barcelona, España: Paidós.

Apple, Michael. (1997b). Teoría crítica y educación. Madrid, España: Niño y Dávila Editores

Beyer, Landon; y Liston, Daniel. (2001). El currículo en conflicto. Visiones sociales, Agenda Educativa y reformas educativas progresistas. Madrid, España: AKAL.

Bourdieu, Pierre. (1997). Capital cultural, escuela y espacio social. Distrito Federal, México: Siglo Veintiuno.

Bourdieu, Pierre. y Passeron, Jean. (2001). La Reproducción. Elementos para una Teoría del Sistema de Enseñanza. Madrid, España: Popular.

Cabello, Josefa. (2003). Imaginar e instituir la educación globalizada. En Jaume Martínez (coord.), Ciudadanía, poder y educación. Madrid, España: GRAO.

Durkheim, Émile. (1975). Educación y Sociología. Madrid, España: Península. 
Escudero, Juan; Bolívas, Antonio; Guarro, Amador; Moreno, Juan; Area, Manuel y Santana, Joel. (2000). Diseño, desarrollo e innovación del currículum. Madrid, España: Síntesis Educativa.

Flecha, José Ramón. (1997). Los profesores como intelectuales: hacia una formación integral de los maestros del siglo XXI. Revista Interuniversitaria de Formación Profesional, 29, 67-76.

Freire, Paulo. (2015a). La Pedagogía del Oprimido. Recuperado de http://www.ensayistas.org/critica/liberacion/varios/freire.pdf

Freire, Paulo. (2015b). La educación como práctica de libertad. Recuperado de http://www.lugaradudas.org/pdf/iconoclasistas paulo freire.pdf

Freire, Paulo. (2012). Pedagogía de la Indignación. Buenos Aires, Argentina: Siglo Veintiuno.

Freire, Paulo. (2008). Cartas a quien pretende enseñar. Buenos Aires, Argentina: Siglo XXI

Freire, Paulo. (2006). Pedagogía de la autonomía: Saberes necesarios para la práctica educativa. México, D.F, México: Siglo XXI.

Freire, Paulo. (2005a). Pedagogía del Oprimido. México, D.F: Siglo XXI

Freire, Paulo. (2005b). Cartas a quien pretende enseñar. México, D.F: Siglo XXI

Freire, Paulo. (2005c). Pedagogía de la esperanza. México, D.F: Siglo Veintiuno

Freire, Paulo. (2004a). El grito manso. México, D.F: Siglo XXI.

Freire, Paulo. (2001). Política y Educación. México, D.F, México: Siglo XXI.

Gimeno, José. (2010a). ¿Qué significa el currículum?. En José Gimeno (comp.), Saberes e incertidumbres sobre el currículum (pp. 21-44). Madrid, España: Morata

Gimeno, José. (2010b). El currículum en la sociedad de la información y del conocimiento. En: Gimeno, José. (comp). Saberes e incertidumbres sobre el currículum, (pp. 180202). Madrid, España: Morata

Gimeno, José. (2001). El curriculum: una reflexión sobre la práctica. España: Morata.

Gimeno, José. (2000). Diseño del currículum, diseño de la enseñanza. El papel de los profesores. En José Gimeno y Ángel Pérez, Comprender y transformar la enseñanza (pp.227-266). Madrid: Morata.

Gimeno, José. (1997). La pedagogía por objetivos: Obsesión por la eficiencia. Madrid, España: Morata.

Giroux, Henry. (2006). La escuela y la lucha por la ciudadanía. Pedagogía crítica de la época moderna. México, D.F; México: Siglo XXI. 
Giroux, Henry. (2003). Teoría y resistencia en educación. México, D.F, México: Siglo XXI.

Giroux, Henry. (1997). Cruzando los límites. Trabajadores culturales y políticas educativas. Barcelona: Paidós.

Giroux, Henry. (1990). Los profesores como intelectuales. Barcelona, España: Paidós.

Giroux, Henry y McLaren, Peter. (1998). Lenguaje, escolarización y subjetividad: más allá de una pedagogía de reproducción y resistencia. En Henry Giroux y Peter McLaren, Sociedad, cultura y educación (pp. 75-103). Madrid, España: Niño y Dávila Editores.

Gvirtz, Silvana y Palamidessi, Mariano. (1998). El ABC de la tarea docente: currículum y enseñanza. Argentina: AIQUE. Recuperado de http://www.atencapital.org.ar/sites/default/files/Ensenanza.pdf

House, Ernest. (1999). La política educativa en una época de productividad. En Pablo Manzano (coord.), Volver a pensar la educación (pp. 112-127). Madrid, España: Morata.

House, Ernest (1997). Evaluación, ética y poder. Madrid, España: Morata.

House, Ernest y Howe, Kenneth. (2001). Valores en evaluación e investigación social. Madrid, España: Morata.

Kemmis, Stephen. (1998). El currículum: más allá de la teoría de la reproducción. Madrid, España: Morata.

Magendzo, Abraham. (2008). Dilemas del currículum y la pedagogía: analizando la Reforma Curricular desde una perspectiva crítica. Santiago, Chile: LOM.

Pérez, Ángel. (2000a). Las funciones sociales de la escuela: de la reproducción a la reconstrucción crítica del conocimiento y la experiencia. En José Gimeno y Ángel Pérez, Comprender y transformar la enseñanza (pp. 12-43). Madrid, España: Morata.

Pérez, Ángel. (2000b). El aprendizaje escolar: la didáctica operatoria a la reconstrucción de la cultura en el aula. En José Gimeno y Ángel Pérez. Comprender y transformar la enseñanza (pp. 102-131). España: Morata.

Rousseau, Jean. (1985). Emilio. Madrid, España: Biblioteca EDAF.

Santos, Miguel. (2003). Arte y Parte. Desarrollar la democracia en las escuelas. Madrid, España: Homo Sapiens.

Santos, Miguel. (1999). Democracia escolar o el problema de la nieve frita. En Pablo Manzano (coord.), Volver a pensar la educación (pp. 128-141). Madrid: Morata.

Santos, Miguel. (1995). La evaluación: un proceso de diálogo comprensión y mejora. Madrid, España: Aljibe. 
Stenhouse, Lawrence. (2003). Investigación y desarrollo del currículum. Madrid, España: Morata.

Sotelo, Ignacio. (1999). Educación y democracia. En Pablo Manzano (coord.), Volver a pensar la educación. (pp. 34-59). Madrid, España: Morata.

Torres, Jurjo. (1998). El currículum oculto. Madrid, España: Morata. 
Revista indizada en
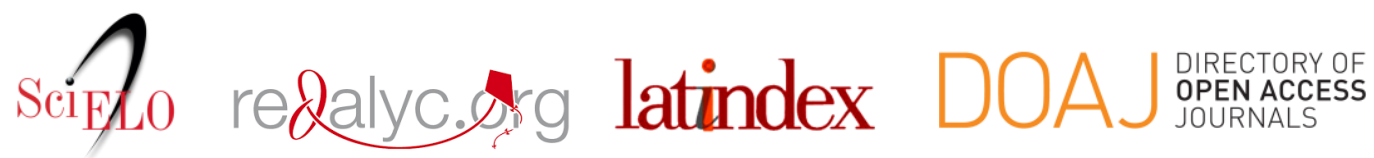

Distribuida en las bases de datos:

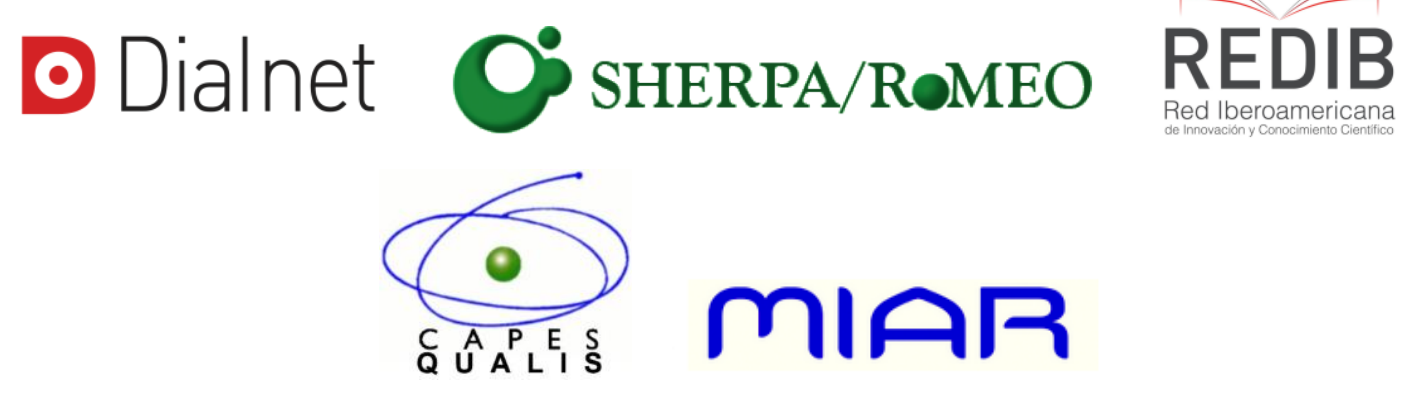

